\title{
Review Article \\ Recent Advances in Studies on the Therapeutic Potential of Dietary Carotenoids in Neurodegenerative Diseases
}

\author{
Kyoung Sang Cho $\mathbb{D}^{1},{ }^{1}$ Myeongcheol Shin $\mathbb{D}^{1},{ }^{1}$ Sunhong Kim $\mathbb{D}^{2,3}$ and Sung Bae Lee $\mathbb{D}^{4}$ \\ ${ }^{1}$ Department of Biological Sciences, Konkuk University, Seoul 05029, Republic of Korea \\ ${ }^{2}$ Disease Target Structure Research Center, Korea Research Institute of Bioscience and Biotechnology, \\ Daejeon 34141, Republic of Korea \\ ${ }^{3}$ Department of Bioscience, University of Science and Technology, Daejeon 34113, Republic of Korea \\ ${ }^{4}$ Department of Brain and Cognitive Sciences, DGIST, Daegu 42988, Republic of Korea \\ Correspondence should be addressed to Sunhong Kim; sunhong@kribb.re.kr and Sung Bae Lee; sblee@dgist.ac.kr
}

Received 22 November 2017; Revised 22 February 2018; Accepted 13 March 2018; Published 16 April 2018

Academic Editor: Julio B. Daleprane

Copyright (c) 2018 Kyoung Sang Cho et al. This is an open access article distributed under the Creative Commons Attribution License, which permits unrestricted use, distribution, and reproduction in any medium, provided the original work is properly cited.

Carotenoids, symmetrical tetraterpenes with a linear C40 hydrocarbon backbone, are natural pigment molecules produced by plants, algae, and fungi. Carotenoids have important functions in the organisms (including animals) that obtain them from food. Due to their characteristic structure, carotenoids have bioactive properties, such as antioxidant, anti-inflammatory, and autophagy-modulatory activities. Given the protective function of carotenoids, their levels in the human body have been significantly associated with the treatment and prevention of various diseases, including neurodegenerative diseases. In this paper, we review the latest studies on the effects of carotenoids on neurodegenerative diseases in humans. Furthermore, animal and cellular model studies on the beneficial effects of carotenoids on neurodegeneration are also reviewed. Finally, we discuss the possible mechanisms and limitations of carotenoids in the treatment and prevention of neurological diseases.

\section{Introduction}

Carotenoids are natural pigments present in various organisms, such as plants, animals, and microorganisms. For example, the orange color of carrots and the red color of tomatoes are due to their carotenoid components [1]. Plant, algae, and fungi produce $>600$ different types of carotenoids. Animals obtain carotenoids from food since they cannot synthesize them. As pigment molecules, carotenoids play a role in the process of photosynthesis, either in photoprotection or light collection [2]. Carotenoids confer photoprotection by dissipating light energy that is not used directly for photosynthesis, and they contribute to photosynthesis through light collection, during which they pass light through to the chloroplast [2]. Carotenoids also act as antioxidants that reduce reactive by-products, such as reactive oxygen species (ROS), during photosynthesis [3]. As a result, carotenoids protect the photosynthetic apparatus from oxidative damage. In addition, carotenoids play various other roles in nature, including the development and oxidative stress signaling in plants, sex-related coloration patterns, and as a precursor for vitamin $\mathrm{A}$ in many species $[3,4]$.

Carotenoids, also known as tetraterpenoids, are C40 hydrocarbons that have isoprenoids as building units (Table 1). The C40 carbon skeleton of carotenoids is produced by the linkage of two C20 geranylgeranyl diphosphate molecules; all of the carotenoid variants are derived from the skeleton [4]. Carotenoids can be divided into two groups according to their polarity: xanthophylls (polar carotenoids such as astaxanthin, $\beta$-cryptoxanthin, lutein, and zeaxanthin) and carotene (nonpolar carotenoids such as $\alpha$-carotene, $\beta$-carotene, and lycopene) [5]. The distinctive structural feature of carotenoids is the long, alternating double and single bond system, which is associated with light absorption and oxidation [4]. 
TABLE 1: Representative food-derived carotenoids and their structures.

\begin{tabular}{|c|c|c|c|}
\hline Carotenoid & Structure & Food source & Reference \\
\hline$\alpha$-Carotene & & Banana, butternut, carrot, pumpkin & {$[11,153-156]$} \\
\hline$\beta$-Carotene & & $\begin{array}{l}\text { Apricots, banana, broccoli, cantaloupe, } \\
\text { carrot, dairy products, honeydew, kale, } \\
\text { mango, nectarine, peach, pumpkin, } \\
\text { spinach, sweet potato, tomato }\end{array}$ & {$[1,11,13,153,154]$} \\
\hline Crocetin & & Gardenia fruit, saffron stigma & {$[157,158]$} \\
\hline Crocin & & Gardenia fruit, saffron stigma & {$[159,160]$} \\
\hline$\beta$-Cryptoxanthin & & $\begin{array}{l}\text { Apple, broccoli, celery, chili, crustaceans, } \\
\text { grape, green beans, papaya, pea, peach, } \\
\text { peppers, salmonid fish, squashes, tangerine }\end{array}$ & {$[11,12,14,153,161]$} \\
\hline Lutein & & $\begin{array}{l}\text { Apple, basil, broccoli, celery, crustaceans, } \\
\text { cucumber, dairy products, grapes, green } \\
\text { pepper, kale, kiwi, maize, parsley, pea, } \\
\text { pumpkin, salmonid fish, spinach, squash }\end{array}$ & {$[1,11,12,162,163]$} \\
\hline Lycopene & & Grapefruit, guava, tomato, watermelon & {$[1,11,153,164,165]$} \\
\hline Zeaxanthin & & $\begin{array}{l}\text { Basil, crustaceans, cucumber, dairy } \\
\text { products, honeydew, kale, maize, mango, } \\
\text { orange, parsley, salmonid fish, spinach }\end{array}$ & {$[1,11,12,162]$} \\
\hline Marine & & & \\
\hline Astaxanthin & & Crustaceans, algae, salmonid fish & {$[12,14,15,36]$} \\
\hline Fucoxanthin & & Brown seaweeds & {$[16,17,166]$} \\
\hline
\end{tabular}

The major sources of carotenoids in the human diet are fruits and vegetables, which have various colors, such as green, red, orange, and yellow [6]. Humans consume approximately 40 carotenoids from common fruits and vegetables (Table 1) [7]. Dark green vegetables, such as broccoli, coriander, kale, and spinach, contain a large number of chloroplasts, in which most carotenoids exist; therefore, they possess high concentrations of carotenoids [8]. As chloroplasts generally contain the most consistent carotenoid composition [9], the distribution of carotenoids is similar among different plant species in this group [7]. On the other hand, in red-, orange-, or yellow-colored fruits and vegetables, carotenoids are mainly accumulated in chromoplasts, which are usually converted from chloroplasts during ripening [10]. As chromoplasts in different plant species contain various carotenoids, the carotenoid distribution in this group is diverse [6]. Some seafood and animal foods also contain carotenoids. Animals cannot synthesize carotenoids; instead, they ingest carotenoids through foods and accumulate these molecules in their bodies. As a result, some animal foods contain carotenoids. For example, high concentrations of lutein and zeaxanthin accumulate in egg yolks [11]. Milk and dairy products, salmonid fish, and crustaceans also provide various carotenoids [12]. The main carotenoid in bovine milk is $\beta$ carotene [13], whereas the major carotenoids in salmonid fish and crustaceans are astaxanthin and canthaxanthin [12, $14,15]$. In addition, some edible brown seaweeds contain fucoxanthin as a major carotenoid [16, 17].

Carotenoids are differentially distributed in various organs of the human body. Interestingly, xanthophylls account for $66-77 \%$ of the total carotenoids in the frontal and occipital lobes of the human brain [18], whereas less than $40 \%$ of the total carotenoids in most tissues and plasma are reported to be xanthophylls [19-21]. It was reported that 
the human brain contains sixteen carotenoids, with the major carotenoids being anhydrolutein, $\alpha$-carotene, $\alpha$-cryptoxanthin, cis- and trans- $\beta$-carotene, $\beta$-cryptoxanthin, lutein, cis- and trans-lycopene, and zeaxanthin [18]. Given their property of protecting tissues from oxidative stress and their localization in the brain, the role of carotenoids in preventing or treating oxidative stress-associated diseases, including neurodegenerative diseases, is of interest.

As carotenoids have various physiological activities, such as antioxidant activity, the amount of carotenoid in the human body is important for health. Therefore, the intake of carotenoids through the diet is associated with the prevention and treatment of various diseases, including age-related macular degeneration [22], cancer [23, 24], cardiovascular diseases [25], and neurodegenerative diseases [5]. In the present paper, we review the latest studies that show the effects of dietary carotenoids on neurodegenerative diseases, and discuss the prospect of the use of carotenoids in the prevention and treatment of these diseases.

\section{Bioactivities of Carotenoids}

As stated above, most carotenoids have a symmetrical tetraterpene structure with a linear C40 hydrocarbon backbone (Table 1). These highly unsaturated fatty chains are susceptible to modifications, such as cis-trans isomerization or cyclization, and result in the characteristic coloration induced by light absorption. Owing to their highly lipophilic structures, carotenoids are found in the lipid membrane. Nonpolar carotenes reside in the inner part of the membrane, whereas polar xanthophylls are located across the bilayer, tilted $\sim 40^{\circ}$ from the axis normal to the membrane plane [26, 27]. Inserted carotenoids may affect the physical properties of the lipid bilayer; however, their exact function in the membrane remains unclear besides in their prevention of the oxidative damage of lipids [27]. Significant evidence has shown that carotenoids can reduce oxidative damage by scavenging ROS and exert anti-inflammatory effects in vivo (Table 2) [28].

2.1. Antioxidant Activity. Carotenoids have been demonstrated to be one of the most potent natural singlet oxygen scavengers, with a fast quenching rate $\left(\cong 10^{10} \mathrm{M}^{-1} \mathrm{~s}^{-1}\right)$ [29]. They can effectively neutralize ROS and other free radicals to provide protection against oxidation in both photosynthetic and nonphotosynthetic organisms [6, 16, 29-37]. However, each carotenoid shows different antioxidant activities, owing to the presence of functional groups with increasing polarities as well as the number of conjugated double bonds [31]. The antioxidant property of carotenoids has inspired many epidemiological and clinical studies that have investigated if these pigment molecules are able to prevent various ROS-mediated disorders such as cancer, inflammation, retinal degeneration, and neurodegeneration. In the case of cancer, many studies have shown that carotenoid consumption is correlated with a reduced risk of several types of cancer; however, other studies have shown that the cancer-preventive effects of carotenoids are negligible or even that they are carcinogenic $[38,39]$.
Lutein is a xanthophyll and the most abundant carotenoid in the human retina and brain $[18,40]$. The Age-Related Eye Disease Study (AREDS) showed that a formulation consisting of vitamins $\mathrm{C}, \mathrm{E}, \beta$-carotene, and zinc is beneficial for the prevention of age-related macular degeneration (AMD) [41]. In a second study, although primary analysis from the AREDS2 did not reveal a benefit of daily supplementation with lutein/ zeaxanthin on AMD progression [42], secondary exploratory analyses suggested that lutein/zeaxanthin were helpful in reducing this risk [43]. In addition, given that increased oxidative stress and inflammation are observed in age-related macular degeneration [44], lutein supplementation may improve visual function through antioxidant activity.

In addition to their antioxidant activities, carotenoids can protect cells from the oxidative stress induced by some stressors via activation of endogenous antioxidant enzymatic activities and a reduction in DNA damage. Crocetin, a pharmacologically active metabolite of Crocus sativus L., exerts cardioprotective effects by increasing superoxide dismutase (SOD) and glutathione peroxidase activities in cardiac hypertrophy induced by norepinephrine in rats [35]. Crocin, another component of Crocus sativus L., has also been shown to increase SOD activity to prevent the death of PC-12 cells during serum/glucose deprivation [34]. Recent studies have demonstrated that marine carotenoids such as astaxanthin and fucoxanthin also display antioxidant properties by activating the antioxidant network, including SOD and catalase $[45,46]$. In addition, $\beta$-cryptoxanthin protects human cells from $\mathrm{H}_{2} \mathrm{O}_{2}$-induced damage by stimulating the repair of damage caused by DNA oxidation as well as by its antioxidant activity [36]. Lycopene and $\beta$-carotene also provide protection against DNA damage at low concentrations [32]. However, opposite effects have been shown at higher concentrations in cells with oxidative damage [32].

2.2. Antineuroinflammation. Neuroinflammation is a local response of the nervous system during neurodegeneration, trauma, and autoimmune disorders. A variety of cell types, including astrocytes, microglia, vascular cells, neutrophils, and macrophages, are involved in neuroinflammation [47]. Growing evidence suggests that neuroinflammation is one of the pathological features of many neurodegenerative disorders and autoimmune diseases, such as multiple sclerosis $[44,47,48]$. In the last decade, some carotenoids have been shown to have antineuroinflammatory effects in vivo. Among the polar xanthophylls, the ability of lutein to suppress inflammation has been demonstrated in murine retinal cells [49-51] and in a clinical trial studying retinal health in preterm infants [52]. In addition, it has been shown that lutein reduces lipid peroxidation and proinflammatory cytokine release by suppressing the activation of the nuclear factor$\kappa \mathrm{B}(\mathrm{NF}-\kappa \mathrm{B})$ pathway in the presence of a variety of oxidative stressors [53-56]. It has also been demonstrated that crocin and crocetin are able to suppress the production of proinflammatory cytokines and nitric oxide by lipopolysaccharide, interferon $\gamma$, and $\beta$-amyloid $(\mathrm{A} \beta)$ stimulation in microglial cells [57]. Astaxanthin, a member of the xanthophyll family that confers the pink color in flamingos, has an antiinflammatory effect and antioxidant activity similar to other 
TABLE 2: Bioactivities of representative food-derived carotenoids and their implications in neurodegenerative diseases.

\begin{tabular}{|c|c|c|c|c|}
\hline Carotenoid & Bioactivity & Reference & Implication in ND & Reference \\
\hline \multirow{2}{*}{$\alpha$-Carotene } & \multirow{2}{*}{ Antioxidant } & \multirow{2}{*}[6,31]{} & AD: human & {$[130]$} \\
\hline & & & PD: human & {$[137,138]$} \\
\hline \multirow{3}{*}{$\beta$-Carotene } & \multirow{3}{*}{ Antioxidant } & \multirow{3}{*}[6,30,31]{} & AD: human & {$[130,134,135$} \\
\hline & & & PD: rodent & {$[137,138]$} \\
\hline & & & ALS: cell & [113] \\
\hline \multirow{2}{*}{ Crocetin } & Antioxidant & {$[35]$} & \multirow{2}{*}{ AD: cell } & \multirow{2}{*}[121,125]{} \\
\hline & Antineuroinflammation & {$[54]$} & & \\
\hline \multirow[t]{5}{*}{ Crocin } & Antioxidant & {$[34]$} & AD: rodent & {$[115]$} \\
\hline & Antineuroinflammation & {$[57]$} & Cell & [114] \\
\hline & & & PD: rodent & {$[117,118]$} \\
\hline & Autophagy & {$[71]$} & Drosophila & [119] \\
\hline & & & Cell & [116] \\
\hline \multirow[t]{2}{*}{$\beta$-Cryptoxanthin } & Antioxidant & {$[6,36]$} & $\mathrm{AD}$ : human & [130] \\
\hline & Antioxidant & {$[6,31]$} & $\mathrm{AD}$ : human & [130-133] \\
\hline \multirow[t]{5}{*}{ Lutein } & Antineuroinflammation & {$[49-51,53]$} & PD: rodent & [167] \\
\hline & Autophagy & [68-70] & HD: rodent & [168] \\
\hline & Antioxidant & {$[6,31]$} & AD: human & {$[130,133]$} \\
\hline & Antineuroinflammation & {$[64,66]$} & Rodent & {$[36,89,91]$} \\
\hline & & & C. elegans & [104] \\
\hline \multirow{5}{*}{ Lycopene } & \multirow{5}{*}{ Autophagy } & \multirow{5}{*}[72-74]{} & Cell & {$[100-102]$} \\
\hline & & & PD: human & {$[138]$} \\
\hline & & & Rodent & [92-95] \\
\hline & & & Cell & [103] \\
\hline & & & HD: rodent & [96-99] \\
\hline Zeaxanthin & Antioxidant & {$[6,31]$} & AD: human & {$[132,133]$} \\
\hline \multicolumn{5}{|l|}{ Marine } \\
\hline \multirow{5}{*}{ Astaxanthin } & Antioxidant & {$[6,31,33]$} & $\mathrm{AD}$ : human & [134] \\
\hline & Antineuroinflammation & {$[58,59,62]$} & Cell & {$[107,108]$} \\
\hline & & & PD: rodent & [110] \\
\hline & Autophagy & {$[75,76]$} & Cell & [109-112] \\
\hline & & & ALS: cell & [113] \\
\hline \multirow{3}{*}{ Fucoxanthin } & Antioxidant & {$[16]$} & AD: rodent & {$[106]$} \\
\hline & Antineuroinflammation & {$[63]$} & Cell & {$[105]$} \\
\hline & Autophagy & [77] & & \\
\hline
\end{tabular}

carotenoids [58, 59]. Furthermore, astaxanthin has also been found to reduce hippocampal and retinal inflammation in streptozotocin-induced diabetic rats, alleviating cognitive deficits, retinal oxidative stress, and depression [60-62]. Fucoxanthin, another member of the marine xanthophylls, exerts anti-inflammatory effects against various stimuli through Akt, NF- $\kappa \mathrm{B}$, and mitogen-activated protein kinase pathways [63].

Lycopene, one of the carotenes present in large amounts in tomatoes, has been demonstrated to reduce neuroinflammatory phenotypes, depression-like behaviors, and inflammation-induced cognitive function defects in murine models [64-66]. As a whole, cellular and animal models have revealed that carotenoids are potent antiinflammatory agents in the nervous system and act through the suppression of inflammation pathways.
2.3. Modulation of Autophagy. Autophagy, a catabolic process necessary for the cleanup of damaged organelles, protein complexes, and even single proteins, as well as for the recycling of nutritional building blocks, has been implicated in numerous disorders and conditions such as aging, cancer, and neurodegeneration. A growing amount of evidence strongly suggests that autophagy removes misfolded or aggregated proteins, the main features of most neurodegenerative diseases, for example, tau fibrils in Alzheimer's disease $(A D)$ and Lewy bodies in Parkinson's disease (PD) [67]. Recent studies have shown that some carotenoids are able to modulate autophagy in cellular and animal models. It has been recently demonstrated that lutein attenuates cobalt chloride-induced autophagy via the mTOR pathway in rat Müller cells [68], whereas it induces autophagy through the upregulation of Beclin-1 in retinal pigment epithelial cells 
$[69,70]$. Crocin has also been shown to have a paradoxical effect on autophagy. The induction of autophagy by crocin occurs during hypoxia, and the inhibition of autophagy by crocin occurs during reperfusion [71]. Lycopene has also been shown to be involved in autophagy [72-74]. Astaxanthin has been found to attenuate autophagy in hepatic cells $[75,76]$. In a model of murine traumatic brain injury, fucoxanthin has the ability to protect neuronal cells from death through the activation of autophagy and the nuclear factor erythroid 2-related factor pathway [77]. The modulation of autophagy by carotenoids remains a controversial topic, and the precise molecular mechanism of this modulation remains unclear.

\section{Beneficial Effects of Carotenoids on Neurodegenerative Diseases}

3.1. Neurodegenerative Diseases. Neurodegenerative diseases are neuronal disorders that feature a progressive loss of neurons and are associated with protein aggregates [78]. The major neurodegenerative diseases include AD, PD, Huntington's disease (HD), and amyotrophic lateral sclerosis (ALS), all of which have disease-specific causative factors and pathological features. For examples, senile plaques with $\mathrm{A} \beta$ aggregates and fibrillary tangles with hyperphosphorylated tau are hallmarks of AD [79]. Similarly, aggregation of $\alpha$-synuclein, huntingtin, and TAR DNA-binding protein 43 is associated with $\mathrm{PD}, \mathrm{HD}$, and ALS, respectively [80-82].

Although these neurodegenerative diseases have different causative factors, they share common features that might be closely related to the onset and progress of disease by the induction of neuronal cell death. One of the shared features is oxidative stress due to elevated ROS production during disease progression [78]. ROS are reactive chemicals with oxygen that can attack and damage the macromolecules, such as lipids, DNA, and proteins, of living cells [83]. In neuronal cells of patients with neurodegenerative diseases, ROS levels are increased by various cellular events, including mitochondrial insults and release of redox metals that interact with oxygen $[84,85]$, which result in neuronal cell death [85]. In addition, the pathological environment of neurodegenerative diseases, such as the increase in protein aggregates, results in sustained inflammation due to microglia activation [86]. Although the inducers of inflammation vary among different diseases, chronic inflammation is induced in neurons through largely common mechanisms [87]. Once neuroinflammation is chronically activated, cytokines and chemokines are released by long-standing activated microglia and oxidative stress is increased, which may be detrimental to neurons [88].

Given that oxidative damage and increased neuroinflammation are critically related with the pathogenesis of and late-onset massive neuronal loss in neurodegenerative diseases, the neuroprotective effect of carotenoids has been of specific interest in the search for effective treatments for these diseases. To provide an update on the latest advances in this field, we have reviewed the papers published in recent years in the following paragraphs.
3.2. Animal and Cellular Model Studies on the Beneficial Effects of Carotenoids on Neurodegenerative Diseases. Controlled animal model or cell culture studies allow for the accurate assessment of the sole influence of carotenoid administration on neurodegenerative diseases that human studies do not. Indeed, numerous experimental studies have recently highlighted the beneficial effects of carotenoids on neurodegenerative diseases (Table 2). Notably, most of these recent experimental studies have focused on either AD or PD.

In the case of well-studied lycopene, administration of lycopene in murine models of $\mathrm{AD}$ leads to the attenuation of mitochondrial oxidative damage [89] and inhibition of $\mathrm{NF}-\kappa \mathrm{B}$ activity and related expression of proinflammatory cytokines in the brain [64], which together may contribute to the suppression of $\mathrm{A} \beta$ formation [90] and improvement of memory retention $[64,89]$. In a recent study that used a tau transgenic mouse model for $\mathrm{AD}$, dietary lycopene supplementation was shown to improve cognitive performance [91]. Similarly, in the context of PD, lycopene-rich tomato powder intake successfully prevented the decline in striatal dopamine levels and degeneration of nigral dopaminergic neurons in rodent models of PD [92, 93]. Consistently, in more recent studies, administration of lycopene was shown to protect against rotenone-induced oxidative stress, neurobehavioral impairments [94], and depletion of dopamine and its metabolites by 1-methyl-4-phenyl-1,2,3,6-tetrahydropyridine [95]. Moreover, the effect of lycopene was also experimentally assessed in vivo in the context of HD. Administration of lycopene alone [96-98], in combination with epigallocatechin-3-gallate [96], or with quercetin and poloxamer 188 [99] showed protective effects against HD-like symptoms induced by 3-nitropropionic acid in rodent models. Consistent with the results obtained from animal model studies, lycopene treatment was also recently shown to be very effective in attenuating neuropathic phenotypes in cultured cell models of AD [100-102] and PD [103]. Interestingly, the beneficial effects of lycopene were also confirmed in a study using a Caenorhabditis elegans model for AD [104].

In addition to lycopene, other dietary carotenoids such as fucoxanthin, astaxanthin, crocin, and crocetin have recently begun to be investigated experimentally for their potential beneficial effects. The beneficial effect of fucoxanthin was recently assessed in the context of $\mathrm{AD}[105,106]$. Moreover, astaxanthin has been shown to protect neurons in the context of various neurodegenerative diseases, including AD [107, 108], PD [109-112], and ALS [113]. Similarly, crocin was recently shown to be beneficial in both $\mathrm{AD}[114,115]$ and PD [116-119]. Other recent studies on crocetin also support the beneficial effects of carotenoids on AD [120-122]. Of note, Tiribuzi et al. [122] used monocytes derived from patients with $\mathrm{AD}$ for analysis, and concluded that trans-crocetin improved the clearance of $\mathrm{A} \beta$ in vitro through the involvement of cathepsin B.

3.3. Human Studies on the Beneficial Effects of Carotenoids on Neurodegenerative Diseases. Consistent with the results obtained from animal and cell culture model studies showing the beneficial effects of carotenoid treatment on 
neurodegenerative diseases, a number of epidemiological studies have also linked the consumption of a carotenoidrich diet with a decreased risk of neurodegenerative diseases in humans (Table 2) [123-126].

The epidemiological correlation between disease risk and carotenoid intake (or its level in the blood) is evident in various neurodegenerative diseases (Table 2). In the case of $\mathrm{AD}$, the most investigated neurodegenerative disease, several studies have reported lower concentrations of carotenoids such as $\beta$-carotene, lutein, and vitamin $\mathrm{A}$ in the blood plasma of $\mathrm{AD}$ patients than in control subjects [127-129]. A very recent case-control study showed that the concentration of six major carotenoids ( $\alpha$-carotene, $\beta$-carotene, $\beta$-cryptoxanthin, lutein, lycopene, and zeaxanthin) in serum was significantly lower in patients with $\mathrm{AD}$ than in cognitively normal control subjects [130]. The results of a study comparing the levels of plasma carotenoids between patients with $\mathrm{AD}$ and normal subjects suggested that maintaining a high level of lutein in relation to plasma lipids can reduce the risk of $\mathrm{AD}$ [131]. Consistently, Nolan et al. [132] concluded that the serum concentrations of lutein, zeaxanthin, and meso-zeaxanthin were significantly lower in AD patients than in control subjects. Similarly, high concentrations of lutein, lycopene, and zeaxanthin in the serum were associated with a lower risk of death from $\mathrm{AD}$ [133].

In addition to blood carotenoid levels, carotenoid intake has also been epidemiologically associated with a reduced risk of $\mathrm{AD}$ and decreased rates of cognitive decline [123-125]. Additional studies have suggested that there are potential beneficial effects of providing carotenoid supplementation to patients with $\mathrm{AD}$ [126]. Kiko et al. [134] and de Oliveira et al. [135] reported that the supply of antioxidant supplements, including astaxanthin and a vitamin complex containing $\alpha$-tocopherol, ascorbic acid, and $\beta$-carotene, reduced $\mathrm{A} \beta$ contents in red blood cells and ROS generation in the cells of $\mathrm{AD}$ patients, respectively. Moreover, a potentially related result was also recently published in an elderly Chinese population, and showed carotenoids to be one of the most highly protective factors against mild cognitive impairment in a cross-sectional study based on a 33-item food frequency questionnaire collected from 2892 elderly subjects [136]. However, the sole influence of carotenoid consumption on the risk or progression of $\mathrm{AD}$ has not yet been clearly established in humans.

Unlike in $\mathrm{AD}$, there have been inconsistencies on the association between carotenoid intake and the reduced risk of PD until very recently. Although a number of epidemiological studies have proposed a possible association between increased intake of both provitamin A and nonprovitamin A carotenoid species and the reduced risk of $\mathrm{PD}$, the risk reduction was small and did not always reach statistical significance [6]. To clarify the inconsistencies observed in human studies, a recent systematic review that analyzed pooled data from relevant papers published between 1990 and 2013 raised the possibility that both $\alpha$ - and $\beta$-carotene levels might be inversely proportional to PD risk [137]. Following this systematic study, a very recent paper by Kim et al. [138] reported that the serum levels of some carotenoids ( $\alpha$-carotene, $\beta$-carotene, and lycopene) were significantly lower in PD patients, and that these carotenoids were inversely correlated with clinical variables representing disease progression. On the contrary, another study reported that the consumption of vitamin $\mathrm{E}$ and carotenoids was not associated with the risk of PD [139]. Thus, more studies are required to draw a solid conclusion on the relationship between carotenoid intake and PD risk reduction.

In the case of ALS, Fitzgerald et al. [140] analyzed pooled results from five published cohort studies on the association between carotenoids and ALS, and suggested that the ingestion of carotenoid-rich foods can prevent or delay the onset of ALS. Consistently, a recent paper published in JAMA Neurology [141] reported that a greater intake of antioxidant nutrients and foods high in carotenoids seems to be associated with more beneficial effects in ALS around the time of diagnosis. Lastly, in the case of HD, there have been no epidemiological studies on carotenoids published in recent years, unlike for the other representative neurodegenerative diseases described above.

Unlike animal model studies, the human studies conducted thus far have focused on the statistical assessment of the epidemiological correlation between the risk of disease and carotenoid intake (or its level in the blood), rather than clinical trials directly measuring the beneficial effects of carotenoid supplementation on the treatment of disease symptoms. However, as can be expected from the in vivo and in vitro bioactivities of carotenoids, a number of studies have shown that various carotenoids have beneficial effects on neurodegenerative diseases.

3.4. Possible Molecular Mechanisms of the Effects of Carotenoids on Neurodegenerative Diseases. Extensive studies suggest that carotenoids may inhibit the onset of neurodegenerative diseases through a variety of mechanisms. The effects of carotenoids have already been studied in different cellular contexts $[28,126,142,143]$ that may have the same working mechanisms as in neurodegenerative diseases. In the case of $\mathrm{AD}$, it has been shown that, through ROS quenching, upregulation of antioxidant enzyme systems, hypocholesterolemic properties, antineuroinflammatory effects, antiamyloid aggregation activity, and regulation of amyloid oligomer-induced signaling, carotenoids may ameliorate mitochondrial dysfunction, oxidative stress, sustained neuroinflammation, impaired lipid metabolism, $\mathrm{A} \beta$ aggregation, and $\mathrm{A} \beta$ neurotoxicity, all of which are critically associated with the pathogenesis of $\mathrm{AD}[63,105,106,144]$. In neurodegenerative disease states, the various mechanisms of action of carotenoids are likely to occur simultaneously. For example, administration of lycopene resulted in the concomitant reduction of $\mathrm{A} \beta$-induced mitochondrial dysfunction, inflammatory cytokine mediators, and caspase- 3 activity in a rat model of AD [64]. Furthermore, astaxanthin treatment reduced $\mathrm{A} \beta$-induced damage in a cultured cell model through several mechanisms including downregulation of apoptotic factors, inhibition of inflammatory cytokine mediating action, and simultaneous reduction of ROS [106].

How can a single substance exhibit these various effects? The functional diversity may be due to the strong antioxidant properties of carotenoids that regulate ROS, key regulators of 
various biological activities. ROS induces functional modification of macromolecules, including lipids, DNA, and proteins, in the aging brains and brains of patients with neurodegenerative diseases [78]. These modifications may affect cellular processes by altering gene expression and signal transduction [145]. For example, the oxidation of PTEN, a lipid phosphatase and suppressor of PI3-kinase pathway, via oxidative stress results in the activation of the NF- $\kappa$ B pathway via $\mathrm{I} \kappa \mathrm{B}$ kinase $(\mathrm{IKK})$ activation [54]. Since NF- $\kappa \mathrm{B}$ regulates the expression of many genes, including oxidative stressresponsive and inflammation-related genes [146], a sustained increase in ROS in the brains of patients with neurodegenerative diseases may lead to an inflammatory response. Therefore, powerful antioxidants, such as carotenoids, can lower the level of ROS to mitigate cellular damage and simultaneously inhibit inflammatory responses by lowering the activity of NF- $\kappa \mathrm{B}$. Indeed, recent studies have shown that various carotenoids suppress inflammation via inhibition of NF- $\kappa \mathrm{B}$ activity $[56,63,147-152]$. Given that oxidative stress and neuroinflammation are crucial to the onset and progress of various neurodegenerative diseases, it is expected that similar working mechanisms may be commonly applied to other neurodegenerative diseases.

In addition to these well-characterized cellular mechanisms of carotenoid functions, the recently proposed carotenoid-mediated regulation of autophagy described above also has a strong potential for protecting neurons in neurodegenerative disease conditions through the reduction of toxic disease proteins conferring neuronal toxicity. However, the role of autophagy in the effects of carotenoids on neurodegenerative diseases remains unclear. Further studies are needed to determine the role that carotenoid-regulated autophagy plays in neuroprotection.

\section{Conclusion}

In this article, we reviewed the recent updates on the beneficial effects of dietary carotenoids on neurodegenerative diseases. An increasing number of papers have demonstrated that dietary carotenoids protect neurons in the context of neurodegenerative diseases through several mechanisms, such as ROS quenching, upregulation of antioxidant enzyme systems, and antineuroinflammatory effects. Indeed, the number of research papers studying the link between carotenoids and neurodegenerative diseases has steadily increased to date. Notably, animal and cell culture model studies have recently begun to be actively conducted, and these model studies strongly support the hypothesis that carotenoid intake may have therapeutic potential in either preventing or ameliorating various neurodegenerative diseases. $\mathrm{AD}$ and $\mathrm{PD}$ have been more thoroughly studied in this regard than other types of rare neurodegenerative diseases (e.g., ALS and HD). In the rodent models of these diseases, administration of certain types of carotenoids, including lycopene, successfully attenuated not only cellular-level phenotypes such as mitochondrial oxidative damage and increased neuroinflammation, but also organism-level phenotypes such as memory impairment and locomotive defects. Of note, the beneficial effects of dietary carotenoids such as astaxanthin, crocin, crocetin, and fucoxanthin on neurodegenerative diseases have been recently studied in animal model systems, broadening our understanding of the association between carotenoid uptake and neurodegenerative diseases.

Although many of the studies presented in this paper demonstrate the beneficial effects of carotenoids as food nutrients on neurodegenerative diseases, some aspects of the carotenoid effect need to be clarified for medical use beyond food nutrients. First, the results of many studies have lacked an accurate analysis of the mechanisms by which carotenoids exert neuroprotective effects. The strong antioxidant properties of carotenoids can explain the neuroprotective effects of carotenoids in that one of the characteristic pathologies in neurodegenerative diseases is increased oxidative stress. However, the mechanisms by which carotenoids inhibit neuroinflammation and activate autophagy have not been thoroughly studied. In addition, many cell studies have shown that some carotenoids regulate the expression of antioxidant and inflammatory proteins, and it is interesting to note how they regulate gene expression. Second, clinical application studies in human patients are required. The causal relationship of the carotenoid effect in human patients can only be clarified by studies of this type. It may also be possible to infer the correlation between carotenoid intake and the onset of disease through comparative studies of races that eat different foods. Finally, in terms of the complexity in the pathogenic mechanisms underlying these diseases, it seems likely that simply increasing the dietary intake of carotenoids may exert only limited protective effects to neurons. For this reason, we expect that future studies determining other neuroprotective reagents/ treatments that confer synergistic effects in combination with carotenoids in neurodegenerative diseases will be essential in finding effective treatments.

\section{Abbreviations}

A $\beta: \quad \beta$-Amyloid

$\mathrm{AD}$ : Alzheimer's disease

ALS: Amyotrophic lateral sclerosis

HD: Huntington's disease

PD: Parkinson's disease

ROS: Reactive oxygen species.

\section{Disclosure}

Sunhong Kim and Sung Bae Lee are cocorresponding authors.

\section{Conflicts of Interest}

The authors declare that they have no conflicts of interest.

\section{Acknowledgments}

This paper was supported by Konkuk University in 2016.

\section{References}

[1] N. I. Krinsky and E. J. Johnson, "Carotenoid actions and their relation to health and disease," Molecular Aspects of Medicine, vol. 26, no. 6, pp. 459-516, 2005. 
[2] B. Demmig-Adams, A. M. Gilmore, and W. Adams, "Carotenoids 3: in vivo function of carotenoids in higher plants," The FASEB Journal, vol. 10, no. 4, pp. 403-412, 1996.

[3] N. Nisar, L. Li, S. Lu, N. C. Khin, and B. J. Pogson, "Carotenoid metabolism in plants," Molecular Plant, vol. 8, no. 1, pp. 68-82, 2015.

[4] G. Britton, "Structure and properties of carotenoids in relation to function," The FASEB Journal, vol. 9, no. 15, pp. 1551-1558, 1995.

[5] J. Widomska, M. Zareba, and W. K. Subczynski, "Can xanthophyll-membrane interactions explain their selective presence in the retina and brain?," Foods, vol. 5, no. 4, p. 7, 2016.

[6] J. Guest and R. Grant, "Carotenoids and neurobiological health," The Benefits of Natural Products for Neurodegenerative Diseases, vol. 12, pp. 199-228, 2016.

[7] F. Khachik, G. R. Beecher, M. B. Goli, and W. R. Lusby, "Separation, identification, and quantification of carotenoids in fruits, vegetables and human plasma by high performance liquid chromatography," Pure and Applied Chemistry, vol. 63, no. 1, pp. 71-80, 1991.

[8] H. E. Khoo, K. N. Prasad, K. W. Kong, Y. Jiang, and A. Ismail, "Carotenoids and their isomers: color pigments in fruits and vegetables," Molecules, vol. 16, no. 2, pp. 1710-1738, 2011.

[9] F. Khachik, G. R. Beecher, and N. F. Whittaker, "Separation, identification, and quantification of the major carotenoid and chlorophyll constituents in extracts of several green vegetables by liquid chromatography," Journal of Agricultural and Food Chemistry, vol. 34, no. 4, pp. 603-616, 1986.

[10] L. Li and H. Yuan, "Chromoplast biogenesis and carotenoid accumulation," Archives of Biochemistry and Biophysics, vol. 539, no. 2, pp. 102-109, 2013.

[11] O. Sommerburg, J. E. E. Keunen, A. C. Bird, and F. J. G. M. van Kuijk, "Fruits and vegetables that are sources for lutein and zeaxanthin: the macular pigment in human eyes," British Journal of Ophthalmology, vol. 82, no. 8, pp. 907-910, 1998.

[12] R. Schweiggert and R. Carle, "Carotenoid deposition in plant and animal foods and its impact on bioavailability," Critical Reviews in Food Science and Nutrition, vol. 57, no. 9, pp. 1807-1830, 2017.

[13] P. J. M. Hulshof, T. van Roekel-Jansen, P. van de Bovenkamp, and C. E. West, "Variation in retinol and carotenoid content of milk and milk products in the Netherlands," Journal of Food Composition and Analysis, vol. 19, no. 1, pp. 67-75, 2006.

[14] B. Bjerkeng, "Carotenoids in aquaculture: fish and crustaceans," Carotenoids, vol. 4, pp. 237-254, 2008.

[15] B. S. Dissing, M. E. Nielsen, B. K. Ersbøll, and S. Frosch, "Multispectral imaging for determination of astaxanthin concentration in salmonids," PLoS One, vol. 6, no. 5, article e19032, 2011.

[16] X. Yan, Y. Chuda, M. Suzuki, and T. Nagata, "Fucoxanthin as the major antioxidant in Hijikia fusiformis, a common edible seaweed," Bioscience, Biotechnology, and Biochemistry, vol. 63, no. 3, pp. 605-607, 1999.

[17] H. Kanda, Y. Kamo, S. Machmudah, and M. Goto, "Extraction of fucoxanthin from raw macroalgae excluding drying and cell wall disruption by liquefied dimethyl ether," Marine Drugs, vol. 12, no. 5, pp. 2383-2396, 2014.

[18] N. Craft, T. Haitema, K. Garnett, K. Fitch, and C. Dorey, "Carotenoid, tocopherol, and retinol concentrations in elderly human brain," The Journal of Nutrition, Health \& Aging, vol. 8, no. 3, pp. 156-162, 2004.

[19] L. Kaplan, J. Lau, and E. Stein, "Carotenoid composition, concentrations, and relationships in various human organs," Clinical Physiology and Biochemistry, vol. 8, no. 1, pp. 1-10, 1990.

[20] D. W. Nierenberg and S. L. Nann, “A method for determining concentrations of retinol, tocopherol, and five carotenoids in human plasma and tissue samples," The American Journal of Clinical Nutrition, vol. 56, no. 2, pp. 417-426, 1992.

[21] K. J. Yeum, S. L. Booth, J. A. Sadowski et al., "Human plasma carotenoid response to the ingestion of controlled diets high in fruits and vegetables," The American Journal of Clinical Nutrition, vol. 64, no. 4, pp. 594-602, 1996.

[22] J. M. Seddon, U. A. Ajani, R. D. Sperduto et al., "Dietary carotenoids, vitamins A, C, and E, and advanced age-related macular degeneration," JAMA, vol. 272, no. 18, pp. 14131420, 1994.

[23] R. G. Ziegler, "A review of epidemiologic evidence that carotenoids reduce the risk of cancer," The Journal of Nutrition, vol. 119, no. 1, pp. 116-122, 1989.

[24] E. Giovannucci, A. Ascherio, E. B. Rimm, M. J. Stampfer, G. A. Colditz, and W. C. Willett, "Intake of carotenoids and retino in relation to risk of prostate cancer," Journal of the National Cancer Institute, vol. 87, no. 23, pp. 1767-1776, 1995.

[25] S. Voutilainen, T. Nurmi, J. Mursu, and T. H. Rissanen, "Carotenoids and cardiovascular health," The American Journal of Clinical Nutrition, vol. 83, no. 6, pp. 1265-1271, 2006.

[26] D. Augustynska, M. Jemioła-Rzemińska, K. Burda, and K. Strzałka, "Influence of polar and nonpolar carotenoids on structural and adhesive properties of model membranes," Chemico-Biological Interactions, vol. 239, pp. 19-25, 2015.

[27] W. Grudzinski, L. Nierzwicki, R. Welc et al., "Localization and orientation of xanthophylls in a lipid bilayer," Scientific Reports, vol. 7, no. 1, p. 9619, 2017.

[28] J. Fiedor and K. Burda, "Potential role of carotenoids as antioxidants in human health and disease," Nutrients, vol. 6, no. 2, pp. 466-488, 2014.

[29] R. Edge, D. McGarvey, and T. Truscott, "The carotenoids as anti-oxidants-a review," Journal of Photochemistry and Photobiology B: Biology, vol. 41, no. 3, pp. 189-200, 1997.

[30] G. W. Burton and K. Ingold, "Beta-carotene: an unusual type of lipid antioxidant," Science, vol. 224, no. 4649, pp. 569-573, 1984.

[31] N. J. Miller, J. Sampson, L. P. Candeias, P. M. Bramley, and C. A. Rice-Evans, "Antioxidant activities of carotenes and xanthophylls," FEBS Letters, vol. 384, no. 3, pp. 240-242, 1996.

[32] G. M. Lowe, L. A. Booth, A. J. Young, and R. F. Bilton, "Lycopene and $\beta$-carotene protect against oxidative damage in HT29 cells at low concentrations but rapidly lose this capacity at higher doses," Free Radical Research, vol. 30, no. 2, pp. 141-151, 1999.

[33] Y. M. Naguib, "Antioxidant activities of astaxanthin and related carotenoids," Journal of Agricultural and Food Chemistry, vol. 48, no. 4, pp. 1150-1154, 2000.

[34] T. Ochiai, S. Ohno, S. Soeda, H. Tanaka, Y. Shoyama, and $\mathrm{H}$. Shimeno, "Crocin prevents the death of rat pheochromyctoma (PC-12) cells by its antioxidant effects stronger than those of $\alpha$-tocopherol," Neuroscience Letters, vol. 362, no. 1, pp. 61-64, 2004. 
[35] X. C. Shen and Z. Y. Qian, "Effects of crocetin on antioxidant enzymatic activities in cardiac hypertrophy induced by norepinephrine in rats," Die Pharmazie-An International Journal of Pharmaceutical Sciences, vol. 61, no. 4, pp. 348-352, 2006.

[36] Y. Lorenzo, A. Azqueta, L. Luna, F. Bonilla, G. Dominguez, and A. R. Collins, "The carotenoid $\beta$-cryptoxanthin stimulates the repair of DNA oxidation damage in addition to acting as an antioxidant in human cells," Carcinogenesis, vol. 30, no. 2, pp. 308-314, 2008.

[37] J. Fiedor, A. Sulikowska, A. Orzechowska, L. Fiedor, and K. Burda, "Antioxidant effects of carotenoids in a model pigment-protein complex," Acta Biochimica Polonica, vol. 59, no. 1, pp. 61-64, 2012.

[38] L. E. Voorrips, R. A. Goldbohm, H. A. Brants et al., “A prospective cohort study on antioxidant and folate intake and male lung cancer risk," Cancer Epidemiology, Biomarkers \& Prevention, vol. 9, no. 4, pp. 357-365, 2000.

[39] K. Athreya and M. F. Xavier, "Antioxidants in the treatment of cancer," Nutrition and Cancer, vol. 69, no. 8, pp. 10991104, 2017.

[40] E. J. Johnson, "Role of lutein and zeaxanthin in visual and cognitive function throughout the lifespan," Nutrition Reviews, vol. 72, no. 9, pp. 605-612, 2014.

[41] Age-Related Eye Disease Study Research Group, "The relationship of dietary carotenoid and vitamin $\mathrm{A}, \mathrm{E}$, and $\mathrm{C}$ intake with age-related macular degeneration in a casecontrol study: AREDS report no. 22," Archives of Ophthalmology, vol. 125, no. 9, pp. 1225-1232, 2007.

[42] Age-Related Eye Disease Study 2 (AREDS2) Research Group, E. Y. Chew, J. P. San Giovanni et al., "Lutein/zeaxanthin for the treatment of age-related cataract: AREDS2 randomized trial report no. 4," JAMA Ophthalmology, vol. 131, no. 7, pp. 843-850, 2013.

[43] The Age-Related Eye Disease Study 2 (AREDS2) Research Group, E. Y. Chew, T. E. Clemons et al., "Secondary analyses of the effects of lutein/zeaxanthin on age-related macular degeneration progression: AREDS2 report no. 3," JAMA Ophthalmology, vol. 132, no. 2, pp. 142-149, 2014.

[44] F. Parmeggiani, M. R. Romano, C. Costagliola et al., "Mechanism of inflammation in age-related macular degeneration," Mediators of Inflammation, vol. 2012, Article ID 435607, 16 pages, 2012.

[45] M. A. Gammone, G. Riccioni, and N. D’Orazio, “Marine carotenoids against oxidative stress: effects on human health," Marine Drugs, vol. 13, no. 10, pp. 6226-6246, 2015.

[46] C. Galasso, C. Corinaldesi, and C. Sansone, "Carotenoids from marine organisms: biological functions and industrial applications," Antioxidants, vol. 6, no. 4, p. 96, 2017.

[47] R. Masgrau, C. Guaza, R. M. Ransohoff, and E. Galea, "Should we stop saying "glia" and "neuroinflammation"?," Trends in Molecular Medicine, vol. 23, no. 6, pp. 486-500, 2017.

[48] P. L. McGeer, E. McGeer, and K. Yasojima, "Alzheimer disease and neuroinflammation," in Advances in Dementia Research, K. Jellinger, R. Schmidt, and M. Windisch, Eds., pp. 53-57, Springer, Vienna, Austria, 2000.

[49] M. Sasaki, Y. Ozawa, T. Kurihara et al., "Neuroprotective effect of an antioxidant, lutein, during retinal inflammation," Investigative Ophthalmology \& Visual Science, vol. 50, no. 3, pp. 1433-1439, 2009.

[50] Q. Bian, S. Gao, J. Zhou et al., "Lutein and zeaxanthin supplementation reduces photooxidative damage and modulates the expression of inflammation-related genes in retinal pigment epithelial cells," Free Radical Biology \& Medicine, vol. 53, no. 6, pp. 1298-1307, 2012.

[51] S. Y. Li, F. K. Fung, Z. J. Fu, D. Wong, H. H. L. Chan, and A. C. Y. Lo, "Anti-inflammatory effects of lutein in retinal ischemic/hypoxic injury: in vivo and in vitro studies," Investigative Ophthalmology \& Visual Science, vol. 53, no. 10, pp. 5976-5984, 2012.

[52] L. P. Rubin, G. M. Chan, B. M. Barrett-Reis et al., "Effect of carotenoid supplementation on plasma carotenoids, inflammation and visual development in preterm infants," Journal of Perinatology, vol. 32, no. 6, pp. 418-424, 2012.

[53] J. E. Kim, R. M. Clark, Y. Park, J. Lee, and M. L. Fernandez, "Lutein decreases oxidative stress and inflammation in liver and eyes of guinea pigs fed a hypercholesterolemic diet," Nutrition Research and Practice, vol. 6, no. 2, pp. 113-119, 2012.

[54] J. H. Kim, H. J. Na, C. K. Kim et al., “The non-provitamin A carotenoid, lutein, inhibits NF- $\kappa$ B-dependent gene expression through redox-based regulation of the phosphatidylinositol 3-kinase/PTEN/Akt and NF- $\kappa \mathrm{B}$-inducing kinase pathways: role of $\mathrm{H}_{2} \mathrm{O}_{2}$ in NF- $\kappa \mathrm{B}$ activation," Free Radical Biology \& Medicine, vol. 45, no. 6, pp. 885-896, 2008.

[55] W. Wu, Y. Li, Y. Wu, Y. Zhang, Z. Wang, and X. Liu, "Lutein suppresses inflammatory responses through Nrf2 activation and NF- $\kappa \mathrm{B}$ inactivation in lipopolysaccharide-stimulated BV-2 microglia," Molecular Nutrition \& Food Research, vol. 59, no. 9, pp. 1663-1673, 2015.

[56] T. Liu, W. H. Liu, J. S. Zhao, F. Z. Meng, and H. Wang, "Lutein protects against $\beta$-amyloid peptide-induced oxidative stress in cerebrovascular endothelial cells through modulation of Nrf-2 and NF- $\kappa \mathrm{B}, "$ Cell Biology and Toxicology, vol. 33, no. 1, pp. 57-67, 2017.

[57] K. N. Nam, Y. M. Park, H. J. Jung et al., "Anti-inflammatory effects of crocin and crocetin in rat brain microglial cells," European Journal of Pharmacology, vol. 648, no. 1-3, pp. 110-116, 2010.

[58] S. Franceschelli, M. Pesce, A. Ferrone et al., "Astaxanthin treatment confers protection against oxidative stress in U937 cells stimulated with lipopolysaccharide reducing $\mathrm{O}_{2}{ }^{-}$ production," PLoS One, vol. 9, no. 2, article e88359, 2014.

[59] X. S. Zhang, X. Zhang, Q. Wu et al., "Astaxanthin offers neuroprotection and reduces neuroinflammation in experimental subarachnoid hemorrhage," Journal of Surgical Research, vol. 192, no. 1, pp. 206-213, 2014.

[60] X. Zhou, F. Zhang, X. Hu et al., "Inhibition of inflammation by astaxanthin alleviates cognition deficits in diabetic mice," Physiology \& Behavior, vol. 151, pp. 412-420, 2015.

[61] P. T. Yeh, H. W. Huang, C. M. Yang, W. S. Yang, and C. H. Yang, "Astaxanthin inhibits expression of retinal oxidative stress and inflammatory mediators in streptozotocininduced diabetic rats," PLoS One, vol. 11, no. 1, article e0146438, 2016.

[62] X. Y. Zhou, F. Zhang, X. T. Hu et al., "Depression can be prevented by astaxanthin through inhibition of hippocampal inflammation in diabetic mice," Brain Research, vol. 1657, pp. 262-268, 2017.

[63] D. Zhao, S. H. Kwon, Y. S. Chun, M. Y. Gu, and H. O. Yang, "Anti-neuroinflammatory effects of fucoxanthin via inhibition of Akt/NF- $\kappa$ B and MAPKs/AP-1 pathways and activation of PKA/CREB pathway in lipopolysaccharide-activated 
BV-2 microglial cells," Neurochemical Research, vol. 42, no. 2, pp. 667-677, 2017.

[64] A. K. Sachdeva and K. Chopra, "Lycopene abrogates A $\beta$ (1-42)-mediated neuroinflammatory cascade in an experimental model of Alzheimer's disease," The Journal of Nutritional Biochemistry, vol. 26, no. 7, pp. 736-744, 2015.

[65] F. Zhang, Y. Fu, X. Zhou et al., "Depression-like behaviors and heme oxygenase-1 are regulated by lycopene in lipopolysaccharide-induced neuroinflammation," Journal of Neuroimmunology, vol. 298, pp. 1-8, 2016.

[66] B. Zhao, B. Ren, R. Guo et al., "Supplementation of lycopene attenuates oxidative stress induced neuroinflammation and cognitive impairment via Nrf2/Nf- $\kappa \mathrm{B}$ transcriptional pathway," Food and Chemical Toxicology, vol. 109, Part 1, pp. 505-516, 2017.

[67] M. A. Rahman and H. Rhim, "Therapeutic implication of autophagy in neurodegenerative diseases," BMB Reports, vol. 50, no. 7, pp. 345-354, 2017.

[68] F. K. Fung, B. Y. Law, and A. C. Lo, "Lutein attenuates both apoptosis and autophagy upon cobalt (II) chloride-induced hypoxia in rat Müller cells," PLoS One, vol. 11, no. 12, article e0167828, 2016.

[69] C. J. Chang, J. F. Lin, C. Y. Hsiao et al., "Lutein induces autophagy via beclin-1 upregulation in IEC-6 rat intestinal epithelial cells," The American Journal of Chinese Medicine, vol. 45, no. 6, pp. 1273-1291, 2017.

[70] S. J. Sheu, J. L. Chen, Y. S. Bee, Y. A. Chen, S. H. Lin, and C. W. Shu, "Differential autophagic effects of vital dyes in retinal pigment epithelial ARPE-19 and photoreceptor 661W cells," PLoS One, vol. 12, no. 3, article e0174736, 2017.

[71] C. Zeng, H. Li, Z. Fan et al., "Crocin-elicited autophagy rescues myocardial ischemia/reperfusion injury via paradoxical mechanisms," The American Journal of Chinese Medicine, vol. 44, no. 3, pp. 515-530, 2016.

[72] M. Buyuklu, F. Kandemir, M. Ozkaraca et al., "Beneficial effects of lycopene against contrast medium-induced oxidative stress, inflammation, autophagy, and apoptosis in rat kidney," Human \& Experimental Toxicology, vol. 34, no. 5, pp. 487-496, 2015.

[73] F. Chen, Z. W. Sun, L. F. Ye, G.-S. Fu, Y. Mou, and S.-J. Hu, "Lycopene protects against apoptosis in hypoxia/reoxygenation-induced H9C2 myocardioblast cells through increased autophagy," Molecular Medicine Reports, vol. 11, no. 2, pp. 1358-1365, 2015.

[74] F. Zhang, S. Xing, and Z. Li, "Antagonistic effects of lycopene on cadmium-induced hippocampal dysfunctions in autophagy, calcium homeostatis and redox," Oncotarget, vol. 8, no. 27, pp. 44720-44731, 2017.

[75] M. Shen, K. Chen, J. Lu et al., "Protective effect of astaxanthin on liver fibrosis through modulation of TGF- $\beta 1$ expression and autophagy," Mediators of Inflammation, vol. 2014, Article ID 954502, 14 pages, 2014.

[76] J. Li, F. Wang, Y. Xia et al., “Astaxanthin pretreatment attenuates hepatic ischemia reperfusion-induced apoptosis and autophagy via the ROS/MAPK pathway in mice," Marine Drugs, vol. 13, no. 6, pp. 3368-3387, 2015.

[77] L. Zhang, H. Wang, Y. Fan et al., "Fucoxanthin provides neuroprotection in models of traumatic brain injury via the Nrf2-ARE and Nrf2-autophagy pathways," Scientific Reports, vol. 7, article 46763, 2017.
[78] K. J. Barnham, C. L. Masters, and A. I. Bush, "Neurodegenerative diseases and oxidative stress," Nature Reviews Drug Discovery, vol. 3, no. 3, pp. 205-214, 2004.

[79] J. Hardy and D. J. Selkoe, "The amyloid hypothesis of Alzheimer's disease: progress and problems on the road to therapeutics," Science, vol. 297, no. 5580, pp. 353-356, 2002.

[80] M. G. Spillantini, M. L. Schmidt, V. M. Y. Lee, J. Q. Trojanowski, R. Jakes, and M. Goedert, " $\alpha$-Synuclein in Lewy bodies,” Nature, vol. 388, no. 6645, pp. 839-840, 1997.

[81] M. Neumann, D. M. Sampathu, L. K. Kwong et al., "Ubiquitinated TDP-43 in frontotemporal lobar degeneration and amyotrophic lateral sclerosis," Science, vol. 314, no. 5796, pp. 130-133, 2006.

[82] F. O. Walker, "Huntington's disease," The Lancet, vol. 369, no. 9557, pp. 218-228, 2007.

[83] B. Halliwell, "Reactive oxygen species in living systems: source, biochemistry, and role in human disease," The American Journal of Medicine, vol. 91, no. 3, pp. S14S22, 1991.

[84] M. T. Lin and M. F. Beal, "Mitochondrial dysfunction and oxidative stress in neurodegenerative diseases," Nature, vol. 443, no. 7113, pp. 787-795, 2006.

[85] B. Uttara, A. V. Singh, P. Zamboni, and R. Mahajan, “Oxidative stress and neurodegenerative diseases: a review of upstream and downstream antioxidant therapeutic options," Current Neuropharmacology, vol. 7, no. 1, pp. 65-74, 2009.

[86] T. Wyss-Coray and L. Mucke, "Inflammation in neurodegenerative disease-a double-edged sword," Neuron, vol. 35, no. 3, pp. 419-432, 2002.

[87] C. K. Glass, K. Saijo, B. Winner, M. C. Marchetto, and F. H. Gage, "Mechanisms underlying inflammation in neurodegeneration," Cell, vol. 140, no. 6, pp. 918-934, 2010.

[88] T. C. Frank-Cannon, L. T. Alto, F. E. McAlpine, and M. G. Tansey, "Does neuroinflammation fan the flame in neurodegenerative diseases?," Molecular Neurodegeneration, vol. 4, no. 1, p. 47, 2009.

[89] A. Prakash and A. Kumar, "Implicating the role of lycopene in restoration of mitochondrial enzymes and BDNF levels in $\beta$-amyloid induced Alzheimer's disease," European Journal of Pharmacology, vol. 741, pp. 104-111, 2014.

[90] S. Katayama, H. Ogawa, and S. Nakamura, "Apricot carotenoids possess potent anti-amyloidogenic activity in vitro," Journal of Agricultural and Food Chemistry, vol. 59, no. 23, pp. 12691-12696, 2011.

[91] L. Yu, W. Wang, W. Pang, Z. Xiao, Y. Jiang, and Y. Hong, "Dietary lycopene supplementation improves cognitive performances in tau transgenic mice expressing P301L mutation via inhibiting oxidative stress and tau hyperphosphorylation," Journal of Alzheimer's Disease, vol. 57, no. 2, pp. 475482, 2017.

[92] H. Suganuma, T. Hirano, Y. Arimoto, and T. Inakuma, "Effect of tomato intake on striatal monoamine level in a mouse model of experimental Parkinson's disease," Journal of Nutritional Science and Vitaminology, vol. 48, no. 3, pp. 251-254, 2002.

[93] V. di Matteo, M. Pierucci, G. Di Giovanni et al., "Intake of tomato-enriched diet protects from 6-hydroxydopamineinduced degeneration of rat nigral dopaminergic neurons," Birth, Life and Death of Dopaminergic Neurons in the Substantia Nigra, vol. 73, pp. 333-341, 2009. 
[94] H. Kaur, S. Chauhan, and R. Sandhir, "Protective effect of lycopene on oxidative stress and cognitive decline in rotenone induced model of Parkinson's disease," Neurochemical Research, vol. 36, no. 8, pp. 1435-1443, 2011.

[95] A. Prema, U. Janakiraman, T. Manivasagam, and A. J. Thenmozhi, "Neuroprotective effect of lycopene against MPTP induced experimental Parkinson's disease in mice," Neuroscience Letters, vol. 599, pp. 12-19, 2015.

[96] P. Kumar and A. Kumar, "Effect of lycopene and epigallocatechin-3-gallate against 3-nitropropionic acid induced cognitive dysfunction and glutathione depletion in rat: a novel nitric oxide mechanism," Food and Chemical Toxicology, vol. 47, no. 10, pp. 2522-2530, 2009.

[97] P. Kumar, H. Kalonia, and A. Kumar, "Lycopene modulates nitric oxide pathways against 3-nitropropionic acid-induced neurotoxicity," Life Sciences, vol. 85, no. 19-20, pp. 711-718, 2009.

[98] R. Sandhir, A. Mehrotra, and S. S. Kamboj, "Lycopene prevents 3-nitropropionic acid-induced mitochondrial oxidative stress and dysfunctions in nervous system," Neurochemistry International, vol. 57, no. 5, pp. 579-587, 2010.

[99] D. Jain and A. Gangshettiwar, "Combination of lycopene, quercetin and poloxamer 188 alleviates anxiety and depression in 3-nitropropionic acid-induced Huntington's disease in rats," Journal of Intercultural Ethnopharmacology, vol. 3, no. 4, pp. 186-191, 2014.

[100] M. Qu, L. Li, C. Chen et al., "Protective effects of lycopene against amyloid $\beta$-induced neurotoxicity in cultured rat cortical neurons," Neuroscience Letters, vol. 505, no. 3, pp. 286-290, 2011.

[101] M. Qu, Z. Jiang, Y. Liao, Z. Song, and X. Nan, "Lycopene prevents amyloid (beta)-induced mitochondrial oxidative stress and dysfunctions in cultured rat cortical neurons," Neurochemical Research, vol. 41, no. 6, pp. 1354-1364, 2016.

[102] S. Hwang, J. W. Lim, and H. Kim, "Inhibitory effect of lycopene on amyloid- $\beta$-induced apoptosis in neuronal cells," Nutrients, vol. 9, no. 12, p. 883, 2017.

[103] F. Yi, X. He, and D. Wang, "Lycopene protects against MPP ${ }^{+}$ induced cytotoxicity by maintaining mitochondrial function in SH-SY5Y cells," Neurochemical Research, vol. 38, no. 8, pp. 1747-1757, 2013.

[104] W. Chen, L. Mao, H. Xing et al., "Lycopene attenuates A $\beta 1-$ 42 secretion and its toxicity in human cell and Caenorhabditis elegans models of Alzheimer disease," Neuroscience Letters, vol. 608 , pp. 28-33, 2015.

[105] J. Lin, J. Yu, J. Zhao et al., "Fucoxanthin, a marine carotenoid, attenuates $\beta$-amyloid oligomer-induced neurotoxicity possibly via regulating the PI3k/Akt and the ERK pathways in SH-SY5Y cells," Oxidative Medicine and Cellular Longevity, vol. 2017, Article ID 6792543, 10 pages, 2017.

[106] S. Xiang, F. Liu, J. Lin et al., "Fucoxanthin inhibits $\beta$-amyloid assembly and attenuates $\beta$-amyloid oligomer-induced cognitive impairments," Journal of Agricultural and Food Chemistry, vol. 65, no. 20, pp. 4092-4102, 2017.

[107] C. H. Chang, C. Y. Chen, J. Y. Chiou, R. Y. Peng, and C. H. Peng, "Astaxanthine secured apoptotic death of PC12 cells induced by $\beta$-amyloid peptide 25-35: its molecular action targets," Journal of Medicinal Food, vol. 13, no. 3, pp. 548556, 2010.

[108] P. Lobos, B. Bruna, A. Cordova et al., "Astaxanthin protects primary hippocampal neurons against noxious effects of
A $\beta$-oligomers," Neural Plasticity, vol. 2016, Article ID 3456783, 13 pages, 2016

[109] Y. Ikeda, S. Tsuji, A. Satoh, M. Ishikura, T. Shirasawa, and T. Shimizu, "Protective effects of astaxanthin on 6hydroxydopamine-induced apoptosis in human neuroblastoma SH-SY5Y cells," Journal of Neurochemistry, vol. 107, no. 6, pp. 1730-1740, 2008.

[110] D. H. Lee, C. S. Kim, and Y. J. Lee, "Astaxanthin protects against $\mathrm{MPTP} / \mathrm{MPP}^{+}$-induced mitochondrial dysfunction and ROS production in vivo and in vitro," Food and Chemical Toxicology, vol. 49, no. 1, pp. 271-280, 2011.

[111] Q. Ye, B. Huang, X. Zhang, Y. Zhu, and X. Chen, "Astaxanthin protects against $\mathrm{MPP}^{+}$-induced oxidative stress in PC12 cells via the HO-1/NOX2 axis," BMC Neuroscience, vol. 13, no. 1, p. 156, 2012.

[112] Q. Ye, X. Zhang, B. Huang, Y. Zhu, and X. Chen, "Astaxanthin suppresses $\mathrm{MPP}^{+}$-induced oxidative damage in PC12 cells through a Sp1/NR1 signaling pathway," Marine Drugs, vol. 11, no. 12, pp. 1019-1034, 2013.

[113] R. Isonaka, H. Hiruma, T. Katakura, and T. Kawakami, "Inhibition of superoxide dismutase selectively suppresses growth of rat spinal motor neurons: comparison with phosphorylated neurofilament-containing spinal neurons," Brain Research, vol. 1425, pp. 13-19, 2011.

[114] A. Ghahghaei, S. Z. Bathaie, H. Kheirkhah, and E. Bahraminejad, "The protective effect of crocin on the amyloid fibril formation of A $\beta 42$ peptide in vitro," Cellular \& Molecular Biology Letters, vol. 18, no. 3, pp. 328-339, 2013.

[115] F. Asadi, A. H. Jamshidi, F. Khodagholi et al., "Reversal effects of crocin on amyloid $\beta$-induced memory deficit: modification of autophagy or apoptosis markers," Pharmacology Biochemistry and Behavior, vol. 139, pp. 47-58, 2015.

[116] G. F. Zhang, Y. Zhang, and G. Zhao, "Crocin protects PC12 cells against $\mathrm{MPP}^{+}$-induced injury through inhibition of mitochondrial dysfunction and ER stress," Neurochemistry International, vol. 89, pp. 101-110, 2015.

[117] M. Hosseini, Z. Rajaei, H. Alaei, and M. Tajadini, “The effects of crocin on 6-OHDA-induced oxidative/nitrosative damage and motor behaviour in hemiparkinsonian rats," The Malaysian Journal of Medical Sciences, vol. 23, no. 6, pp. 35-43, 2016.

[118] Z. Rajaei, M. Hosseini, and H. Alaei, "Effects of crocin on brain oxidative damage and aversive memory in a 6-OHDA model of Parkinson's disease," Arquivos de Neuro-Psiquiatria, vol. 74, no. 9, pp. 723-729, 2016.

[119] S. V. Rao, S. C. Yenisetti, and P. S. Rajini, "Evidence of neuroprotective effects of saffron and crocin in a Drosophila model of parkinsonism," Neurotoxicology, vol. 52, pp. 230-242, 2016.

[120] J. H. Ahn, Y. Hu, M. Hernandez, and J. R. Kim, "Crocetin inhibits beta-amyloid fibrillization and stabilizes betaamyloid oligomers," Biochemical and Biophysical Research Communications, vol. 414, no. 1, pp. 79-83, 2011.

[121] Y. Kong, L. P. Kong, T. Luo et al., "The protective effects of crocetin on A $\beta 1-42$-induced toxicity in Ht22 cells," CNS \& Neurological Disorders-Drug Targets, vol. 13, no. 9, pp. 1627-1632, 2014

[122] R. Tiribuzi, L. Crispoltoni, V. Chiurchiù et al., "trans-Crocetin improves amyloid- $\beta$ degradation in monocytes from Alzheimer's disease patients," Journal of the Neurological Sciences, vol. 372, pp. 408-412, 2017. 
[123] Q. Dai, A. R. Borenstein, Y. Wu, J. C. Jackson, and E. B. Larson, "Fruit and vegetable juices and Alzheimer's disease: the Kame Project," The American Journal of Medicine, vol. 119, no. 9, pp. 751-759, 2006.

[124] F. J. Li, L. Shen, and H. F. Ji, "Dietary intakes of vitamin E, vitamin $\mathrm{C}$, and $\beta$-carotene and risk of Alzheimer's disease: a meta-analysis," Journal of Alzheimer's Disease, vol. 31, no. 2, pp. 253-258, 2012.

[125] E. Kesse-Guyot, V. A. Andreeva, V. Ducros et al., "Carotenoid-rich dietary patterns during midlife and subsequent cognitive function," British Journal of Nutrition, vol. 111, no. 5, pp. 915-923, 2014.

[126] N. M. Honarvar, A. Saedisomeolia, M. Abdolahi et al., "Molecular anti-inflammatory mechanisms of retinoids and carotenoids in Alzheimer's disease: a review of current evidence," Journal of Molecular Neuroscience, vol. 61, no. 3, pp. 289-304, 2017.

[127] Z. Zaman, S. Roche, P. Fielden, P. G. Frost, D. C. Niriella, and A. C. D. Cayley, "Plasma concentrations of vitamins A and E and carotenoids in Alzheimer's disease," Age and Ageing, vol. 21, no. 2, pp. 91-94, 1992.

[128] F. J. Jiménez-Jiménez, J. A. Molina, F. Bustos et al., "Serum levels of $\beta$-carotene, $\alpha$-carotene and vitamin A in patients with Alzheimer's disease," European Journal of Neurology, vol. 6, no. 4, pp. 495-497, 1999.

[129] W. Wang, L. Shinto, W. E. Connor, and J. F. Quinn, "Nutritional biomarkers in Alzheimer's disease: the association between carotenoids, n-3 fatty acids, and dementia severity," Journal of Alzheimer's Disease, vol. 13, no. 1, pp. 31-38, 2008.

[130] K. Mullan, M. A. Williams, C. R. Cardwell et al., "Serum concentrations of vitamin $\mathrm{E}$ and carotenoids are altered in Alzheimer's disease: a case-control study," Alzheimer's \& Dementia: Translational Research \& Clinical Interventions, vol. 3, no. 3, pp. 432-439, 2017.

[131] C. Feart, L. Letenneur, C. Helmer et al., "Plasma carotenoids are inversely associated with dementia risk in an elderly French cohort," The Journals of Gerontology Series A: Biological Sciences and Medical Sciences, vol. 71, no. 5, pp. 683-688, 2016.

[132] J. M. Nolan, E. Loskutova, A. N. Howard et al., "Macular pigment, visual function, and macular disease among subjects with Alzheimer's disease: an exploratory study," Journal of Alzheimer's Disease, vol. 42, no. 4, pp. 1191-1202, 2014.

[133] J. Y. Min and K. B. Min, "Serum lycopene, lutein and zeaxanthin, and the risk of Alzheimer's disease mortality in older adults," Dementia and Geriatric Cognitive Disorders, vol. 37, no. 3-4, pp. 246-256, 2014.

[134] T. Kiko, K. Nakagawa, A. Satoh et al., "Amyloid $\beta$ levels in human red blood cells," PLoS One, vol. 7, no. 11, article e49620, 2012.

[135] B. F. de Oliveira, C. A. Veloso, J. A. Nogueira-Machado et al., "Ascorbic acid, alpha-tocopherol, and beta-carotene reduce oxidative stress and proinflammatory cytokines in mononuclear cells of Alzheimer's disease patients," Nutritional Neuroscience, vol. 15, no. 6, pp. 244-251, 2012.

[136] Y. Lu, Y. An, J. Guo et al., "Dietary intake of nutrients and lifestyle affect the risk of mild cognitive impairment in the Chinese elderly population: a cross-sectional study," Frontiers in Behavioral Neuroscience, vol. 10, article 00229, 2016.

[137] A. Takeda, O. P. Nyssen, A. Syed, E. Jansen, B. Bueno-deMesquita, and V. Gallo, "Vitamin A and carotenoids and the risk of Parkinson's disease: a systematic review and meta-analysis," Neuroepidemiology, vol. 42, no. 1, pp. 2538,2014

[138] J. H. Kim, J. Hwang, E. Shim, E. J. Chung, S. H. Jang, and S. B. Koh, "Association of serum carotenoid, retinol, and tocopherol concentrations with the progression of Parkinson's disease," Nutrition Research and Practice, vol. 11, no. 2, pp. 114-120, 2017.

[139] K. C. Hughes, X. Gao, I. Y. Kim et al., "Intake of antioxidant vitamins and risk of Parkinson's disease," Movement Disorders, vol. 31, no. 12, pp. 1909-1914, 2016.

[140] K. C. Fitzgerald, É. J. O’Reilly, E. Fondell et al., "Intakes of vitamin $\mathrm{C}$ and carotenoids and risk of amyotrophic lateral sclerosis: pooled results from 5 cohort studies," Annals of Neurology, vol. 73, no. 2, pp. 236-245, 2013.

[141] J. W. Nieves, C. Gennings, P. Factor-Litvak et al., “Association between dietary intake and function in amyotrophic lateral sclerosis," JAMA Neurology, vol. 73, no. 12, pp. 14251432, 2016.

[142] S. A. Paiva and R. M. Russell, " $\beta$-Carotene and other carotenoids as antioxidants," Journal of the American College of Nutrition, vol. 18, no. 5, pp. 426-433, 1999.

[143] W. Stahl and H. Sies, "Antioxidant activity of carotenoids," Molecular Aspects of Medicine, vol. 24, no. 6, pp. 345-351, 2003.

[144] J. Lakey-Beitia, D. Doens, D. J. Kumar et al., "Anti-amyloid aggregation activity of novel carotenoids: implications for Alzheimer's drug discovery," Clinical Interventions in Aging, vol. Volume 12, pp. 815-822, 2017.

[145] T. Finkel and N. J. Holbrook, "Oxidants, oxidative stress and the biology of ageing," Nature, vol. 408, no. 6809, pp. 239-247, 2000.

[146] E. M. Conner and M. B. Grisham, "Inflammation, free radicals, and antioxidants," Nutrition, vol. 12, no. 4, pp. 274-277, 1996.

[147] S. Li, X. Liu, J. Lei, J. Yang, P. Tian, and Y. Gao, "Crocin protects podocytes against oxidative stress and inflammation induced by high glucose through inhibition of NF- $\kappa \mathrm{B}$," Cellular Physiology and Biochemistry, vol. 42, no. 4, pp. 1481-1492, 2017.

[148] A. G. Mazumder, P. Sharma, V. Patial, and D. Singh, "Crocin attenuates kindling development and associated cognitive impairments in mice via inhibiting reactive oxygen speciesmediated NF- $\kappa \mathrm{B}$ activation," Basic and Clinical Pharmacology and Toxicology, vol. 120, no. 5, pp. 426-433, 2017.

[149] K. Sahin, C. Orhan, F. Akdemir et al., " $\beta$-Cryptoxanthin ameliorates metabolic risk factors by regulating NF- $\kappa \mathrm{B}$ and Nrf2 pathways in insulin resistance induced by high-fat diet in rodents," Food and Chemical Toxicology, vol. 107, Part A, pp. 270-279, 2017.

[150] F. Wang, N. Wang, Y. Gao et al., “ $\beta$-Carotene suppresses osteoclastogenesis and bone resorption by suppressing NF$\kappa \mathrm{B}$ signaling pathway," Life Sciences, vol. 174, pp. 15-20, 2017.

[151] M. Zhang, Z. Cui, H. Cui, Y. Wang, and C. Zhong, “Astaxanthin protects astrocytes against trauma-induced apoptosis through inhibition of NKCC1 expression via the NF- $\kappa \mathrm{B}$ signaling pathway," BMC Neuroscience, vol. 18, no. 1, p. 42, 2017.

[152] X. Zhou, S. Wang, X. Ding et al., "Zeaxanthin improves diabetes-induced cognitive deficit in rats through activating 
PI3K/AKT signaling pathway," Brain Research Bulletin, vol. 132, pp. 190-198, 2017.

[153] A. R. Mangels, J. M. Holden, G. R. Beecher, M. R. Forman, and E. Lanza, "Carotenoid content of fruits and vegetables: an evaluation of analytic data," Journal of the American Dietetic Association, vol. 93, no. 3, pp. 284-296, 1993.

[154] L. Englberger, I. Darnton-Hill, T. Coyne, M. H. Fitzgerald, and G. C. Marks, "Carotenoid-rich bananas: a potential food source for alleviating vitamin A deficiency," Food and Nutrition Bulletin, vol. 24, no. 4, pp. 303-318, 2003.

[155] L. M. J. de Carvalho, L. de Azevedo Sarmet Moreira Smiderle, J. L. V. de Carvalho, F. de Souza Neves Cardoso, and M. G. B. Koblitz, "Assessment of carotenoids in pumpkins after different home cooking conditions," Food Science and Technology, vol. 34, no. 2, pp. 365-370, 2014.

[156] F. Zaccari and G. Galietta, " $\alpha$-Carotene and $\beta$-carotene content in raw and cooked pulp of three mature stage winter squash "type butternut"," Food, vol. 4, no. 4, pp. 477-486, 2015.

[157] I. A. Lee, J. H. Lee, N. I. Baek, and D. H. Kim, “Antihyperlipidemic effect of crocin isolated from the fructus of Gardenia jasminoides and its metabolite crocetin," Biological and Pharmaceutical Bulletin, vol. 28, no. 11, pp. 2106-2110, 2005.

[158] M. Giaccio, "Crocetin from saffron: an active component of an ancient spice," Critical Reviews in Food Science and Nutrition, vol. 44, no. 3, pp. 155-172, 2004.

[159] T. Q. Pham, F. Cormier, E. Farnworth, V. H. Tong, and M. R. Van Calsteren, "Antioxidant properties of crocin from Gardenia jasminoides Ellis and study of the reactions of crocin with linoleic acid and crocin with oxygen," Journal of Agricultural and Food Chemistry, vol. 48, no. 5, pp. 1455-1461, 2000.

[160] H. Hosseinzadeh, H. R. Sadeghnia, T. Ziaee, and A. Danaee, "Protective effect of aqueous saffron extract (Crocus sativus L.) and crocin, its active constituent, on renal ischemiareperfusion-induced oxidative damage in rats," Journal of Pharmacy \& Pharmaceutical Sciences, vol. 8, no. 3, pp. 387393, 2005.

[161] D. E. Breithaupt and A. Bamedi, "Carotenoid esters in vegetables and fruits: a screening with emphasis on $\beta$-cryptoxanthin esters," Journal of Agricultural and Food Chemistry, vol. 49, no. 4, pp. 2064-2070, 2001.

[162] E. S. M. Abdel-Aal, H. Akhtar, K. Zaheer, and R. Ali, "Dietary sources of lutein and zeaxanthin carotenoids and their role in eye health," Nutrients, vol. 5, no. 4, pp. 1169-1185, 2013.

[163] I. Jaswir, N. Shahidan, R. Othman, Y. Z. Has-Yun Hashim, F. Octavianti, and M. N. . Salleh, "Effects of season and storage period on accumulation of individual carotenoids in pumpkin flesh (Cucurbita moschata)," Journal of Oleo Science, vol. 63, no. 8, pp. 761-767, 2014.

[164] U. Chandrika, K. Fernando, and K. Ranaweera, "Carotenoid content and in vitro bioaccessibility of lycopene from guava (Psidium guajava) and watermelon (Citrullus lanatus) by high-performance liquid chromatography diode array detection," International Journal of Food Sciences and Nutrition, vol. 60, no. 7, pp. 558-566, 2009.

[165] D. P. S. Oberoi and D. S. Sogi, "Utilization of watermelon pulp for lycopene extraction by response surface methodology," Food Chemistry, vol. 232, pp. 316-321, 2017.

[166] K. Miyashita, S. Nishikawa, F. Beppu, T. Tsukui, M. Abe, and M. Hosokawa, "The allenic carotenoid fucoxanthin, a novel marine nutraceutical from brown seaweeds," Journal of the
Science of Food and Agriculture, vol. 91, no. 7, pp. 11661174, 2011.

[167] J. Nataraj, T. Manivasagam, A. J. Thenmozhi, and M. M. Essa, "Lutein protects dopaminergic neurons against MPTPinduced apoptotic death and motor dysfunction by ameliorating mitochondrial disruption and oxidative stress," Nutritional Neuroscience, vol. 19, no. 6, pp. 237-246, 2016.

[168] Y. Binawade and A. Jagtap, "Neuroprotective effect of lutein against 3-nitropropionic acid-induced Huntington's diseaselike symptoms: possible behavioral, biochemical, and cellular alterations," Journal of Medicinal Food, vol. 16, no. 10, pp. 934-943, 2013. 


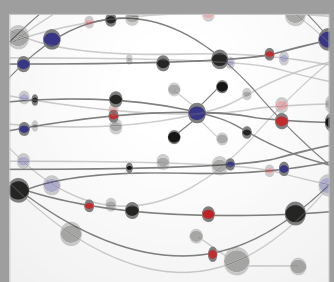

The Scientific World Journal
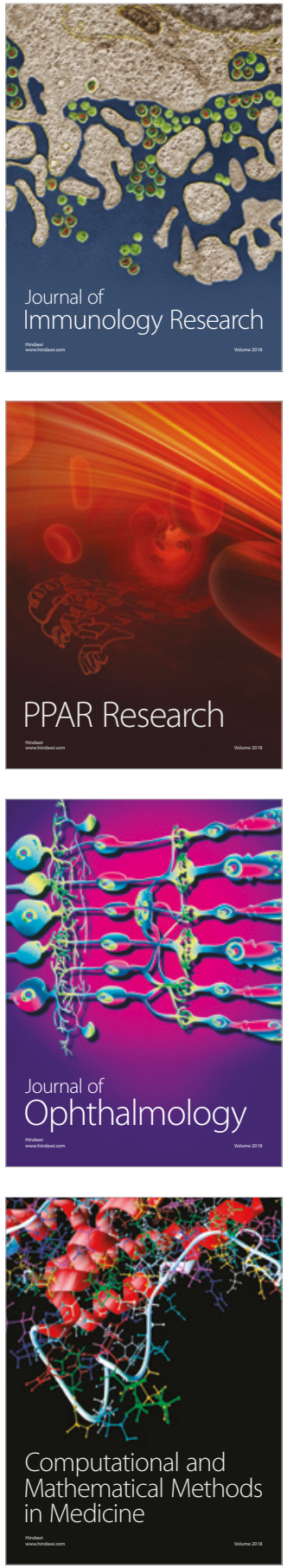

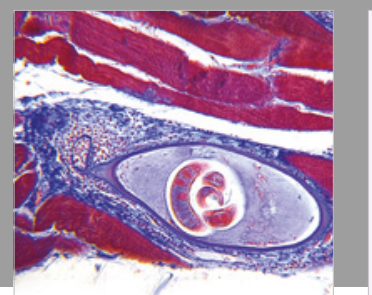

Gastroenterology Research and Practice

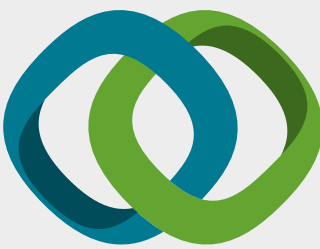

\section{Hindawi}

Submit your manuscripts at

www.hindawi.com
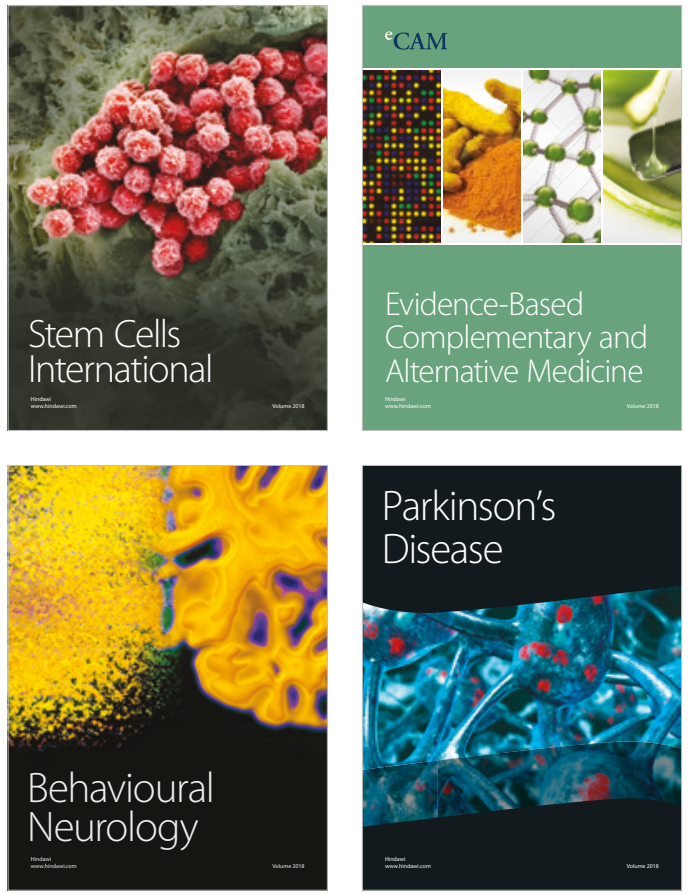

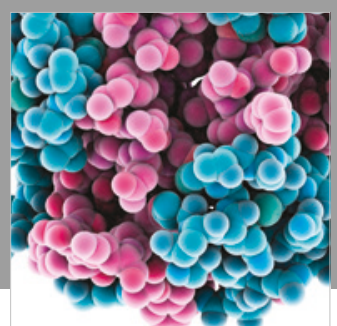

ournal of

Diabetes Research

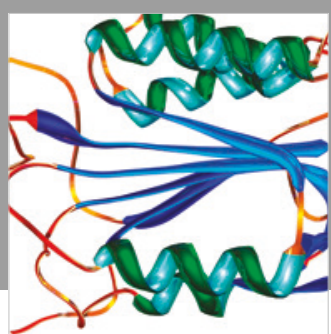

Disease Markers
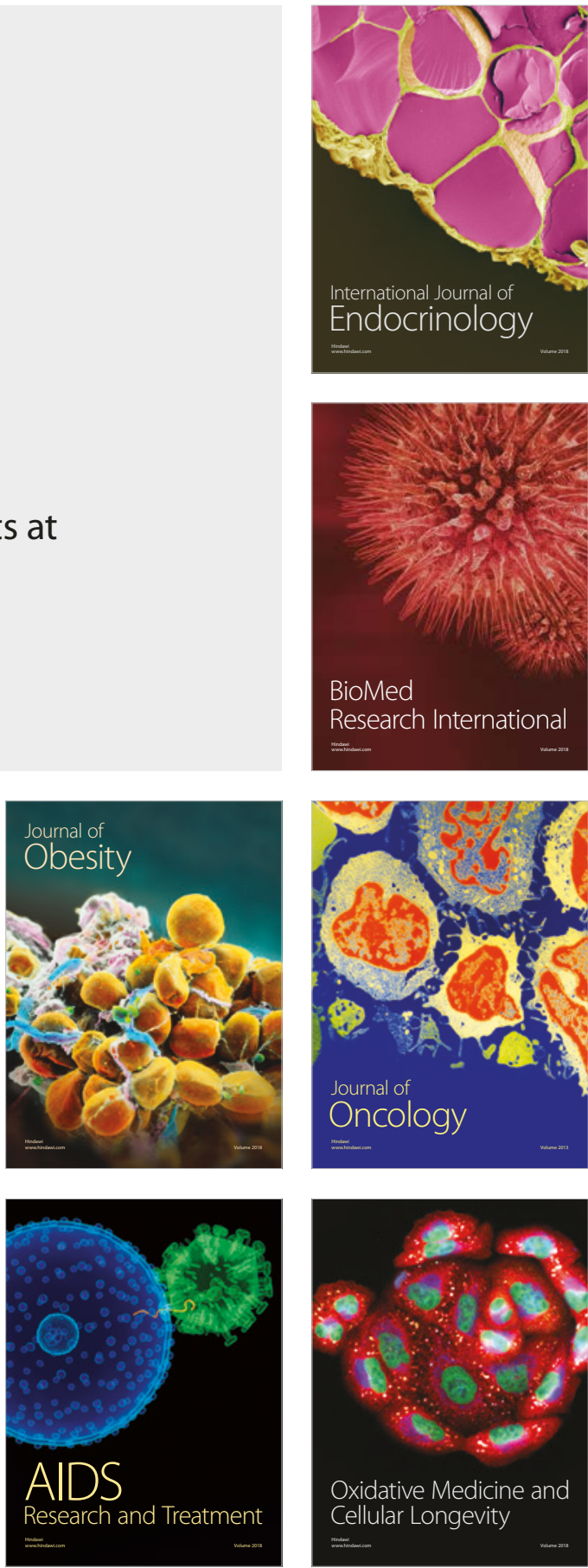